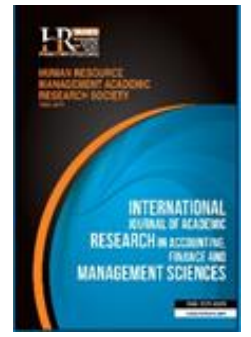

International Journal of Academic Research in Accounting, Finance and Management Sciences

Vol. 9, No.3, July 2019, pp. 274-286

E-ISSN: 2225-8329, P-ISSN: 2308-0337

(C) 2019 HRMARS

www.hrmars.com

To cite this article: Nga'ng'a, E.W., Deya, J. (2019). Influence of Strategic Implementation Drivers on Performance of Tana and Athi Rivers Development Authority in Kenya, International Journal of Academic Research in Accounting, Finance and Management Sciences 9 (3): 274-286

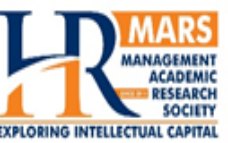

\title{
Influence of Strategic Implementation Drivers on Performance of Tana and Athi Rivers Development Authority in Kenya
}

\author{
Esther Wanjiku Nga'ng'a ${ }^{1}$, Jared Deya ${ }^{2}$ \\ ${ }^{1} \mathrm{Jomo}$ Kenyatta University of Agriculture and Technology, Kenya, \\ ${ }^{1}$ E-mail: estherngmwangi@gmail.com, ${ }^{2}$ E-mail: jdeya@jkuat.ac.ke
}

\begin{abstract}
Successful implementation of strategies by organizations leads to achievement of set performance goals and objectives. This is due to the fact that strategies defines where the organization needs to go, the means to reach there, the required resources and the participants to facilitate realization of the goals. The current study sought to unveil the influence of strategic implementation drivers on performance of Tana and Athi Rivers Development Authority (TARDA). The study sought to establish the influence of resource availability, organizational culture, top management support and government policies on performance of TARDA. The study was informed by Resource Based Theory, Schein's Theory of Organizational culture, Path Goal Leadership Theory and Policy Theory. A descriptive research design was adopted in the study. The target population comprised of employees in top, middle and lower management levels from TARDA's main office with a sample of 189 respondents. Data was collected using structured questionnaires and analyzed by employing descriptive statistics and inferential analysis using SPSS. The findings of the study revealed that resource availability, organizational culture and top management support, positively and significantly influence performance of TARDA. The study however established that government policies negatively influence performance of the Authority. The new policy environment presents various challenges to the Authority. The study recommends that the management of TARDA should focus on availing resources by diversifying its financial resource base and not only relying on the Exchequer for funding, having training sessions on employees before the start of the implementation process and adopting relevant technology during the implementation process. The study also recommends that the management of TARDA should focus on enhancing its organizational culture by offering mentorship programs to junior employees on the ways and means to carry out set activities, establishing structures that guides execution of activities, having a culture that encourages employees loyalty and sense of belonging and having a supportive culture that overcomes internal resistance to change. The study further recommends that the management of TARDA should focus on enhancing its top management support by prioritizing on implementing the strategies, helping employees with means to discharge their duties successfully, practicing participatory leadership and having incentives that positively influence performance of employees in the Authority.
\end{abstract}

Key words

Strategic Implementation drivers, performance

Received: 28 Sep 2019 (C) The Authors 2019

Revised: 10 Oct 2019 Published by Human Resource Management Academic Research Society (www.hrmars.com)

Accepted: 17 Oct 2019 This article is published under the Creative Commons Attribution (CC BY 4.0) license. Anyone may reproduce, distribute, translate and create derivative works of this article (for both commercial and non-commercial purposes), subject to full attribution to the original publication and authors. The full terms of this license may be seen at: http://creativecommons.org/licences/by/4.0/legalcode

\section{Introduction}

The practice and concept of implementing strategies have received worldwide embracement across various economic sectors due to its perceived contribution to operational effectiveness and performance amongst organizations (Strickland and Thompson, 2013). In today's operational environment, private and 
public organizations have seriously adopted the practice of implementing strategies in order to guide performance that culminates into delivery of quality services to the public. According to Heide et al. (2012) strategies in the public sector generally aims at strengthening the effectiveness of various units of governments and directing the units through changes that ensure there is continuity and substantial fit in the dynamic operational environment. This is attained through setting a value chain that allows the users of the government unit to receive services efficiently and effectively and availing transparent accountability to the general public.

Alexander (2011) notes that the implementation which entails translating the strategy into operational and functional actions appears to be one of the most difficult managerial activity faced by many organizations. Many organizations, despite formulating attractive and result oriented strategies face difficulties in implementing the same. In Kenya's public sector, there has been a consistent failure in the implementation of strategies which hinders realization of set goals. Beer and Eisenstat (2010) notes that most sectors only manage to implement $30 \%$ of their strategies. This has culminated to deterioration in the level of services offered in the public sectors. In Netherlands, Langereis (2015) observed that most organizations attached much importance on formulation of strategies as opposed to its implementation. This culminates to utilization of available resources during the formulation stage thus interfering even with resources meant for implementation. Acar (2013) adds that the failure of management to communicate and explain comprehensively the contents of strategy to employees and stakeholders further contributes to failures in the implementation of the strategic plan.

In Kenya, formulation of strategies by organizations aim at outlining the position where a firm needs to be and the goals it needs to achieve in a specific period of time. The strategy also aligns the organization's mission and vision to ensure that the organization functions and achieves its set performance goals (Mueni, 2016). According to Ogonge (2013), despite the efforts, resources and time invested in formulating the strategies, organizations face challenges in implementing the same which affects the general performance. In his study on relationship between strategic planning and organization's performance, Ogonge (2013) noted that successful implementation of strategies is associated with investments on innovations and technology and establishing an effective system of communication in the organization.

\subsection{Statement of the Problem}

TARDA is one of the six Regional Development Authorities (RDA) established under specific Parliamentary Acts in Kenya, mandated to undertake long term integrated land and water based natural resources development planning of the Tana and Athi river Basin, initiate, regulate and coordinate all development activities and actors within the basins for optimal socio-economic welfare of the surrounding people and Kenya at large.

However, a number of constraints over time have inhibited TARDA from achieving its performance objectives. Some of the constraints includes; dwindling Exchequer funding; enactment of overlapping Acts of Parliament occasioned by devolution have resulted into dilution of the mandate of TARDA and diversion of funds to other institutions for activities meant to be implemented by the Authority; the absence of an overarching RDA policy and a reviewed TARDA Act that is aligned with CoK 2010 has led to frequent changes in Ministerial placements that affects business continuity and planning; inadequate development funding and a shift in external funding policy by the government, poor salaries to staff and lack of autonomy. Some of the Counties within TARDA jurisdiction are forming regional economic blocks that are depriving the Authority funding and project initiation opportunities. These challenges triggered the Authority to shift from formulating long term strategies to formulating short term five (5) year strategies. Even with the short term strategies, the Authority still face challenges in implementing the same which inhibits realization of set goals.

According to TARDA Report (2009), the Authority managed to implement $36 \%$ of its first five year strategic plan between 2004 and 2008. In its second strategic plan between 2009 and 2013, the Authority managed to implement only $34 \%$ of its plan (TARDA, 2014). The Authority then implemented its third strategic plan from 2014 to 2018 and based on the qualitative reviews, between $30 \%-40 \%$ of the Strategic Plan objectives were achieved by the end of the implementation period (TARDA, 2018). This indicates that 
there exist drivers that limit the Authority from successfully implementing its strategies which hinders realization of set performance goals.

\subsection{Objectives of the Study}

The general objective of the study sought to establish the influence of strategic implementation drivers on performance of Regional Development Authorities taking a case study of TARDA.

The specific objectives included:

- To examine the influence of resource availability on performance of TARDA in Kenya;

- To establish the influence of organizational culture on performance of TARDA in Kenya;

- To assess the influence of top management support on performance of TARDA in Kenya

- To determine the influence of government policies on performance of TARDA in Kenya.

\subsection{Limitation of the Study}

The study faced challenges during data collection in accessing respondents due to their busy schedules. To mitigate this, the researcher constantly visited the respondents' offices to ascertain the availability of the respondents. Another challenge was on respondents being reluctant in giving information related to the operations of the Authority and for others it was lack of information on TARDA operational Projects.

\section{Literature Review}

\subsection{Theoretical Background}

\subsubsection{Resource Based Theory}

The theory was proposed by Penrose (1959) who viewed firms as bundles of resources that are distinctive and which contribute to competitive advantage. The theory focuses on a firm's capability of establishing relationships that lead to accessibility of resources.

An organization's decision to accomplish certain objectives is bound to be faced by barriers such as scarcity of resources contributed by many organizations competing for similar or same resources. Resources according to Barney (1991) refer to intangible or tangible assets within a firm that are used to execute various activities. The theory further argues that organizations possessing leaders with familiarity on a firm's resource capability outperforms other organizations. The theory contributed to the study by informing the independent variable which is resource availability. For a strategy to be successfully implemented, an organization must capitalize on its available rare, unique and non-imitable resources.

\subsubsection{Schein's Theory of Organizational Culture}

The theory was proposed by Schein in 1980 in a bid to explain why individuals within different organizations act and behave differently. According to the theory, culture is comprised of a process of change and formation which encompasses all facets of functioning in human beings. Additionally, culture revolves around major issues of internal integration and external adaptation of individuals within an organization. Schein (1980) further adds that culture appears as a patterned and interrelated set of assumptions which focuses on crucial issues guiding the operations of the organization. In advancing the theory, Jones and James (2005) views artifacts as organizational defining culture comprising of easily seen, tangible and felt manifestations such as physical environment, technology, ceremonies, published values amongst others. The theory was adopted in the current study as it informs of how composition of culture promotes performance within an organization.

\subsubsection{Path Goal Leadership Theory}

The theory was first proposed by Evans (1970) and proposes that the main functions of a leader consist of illuminating and setting goals on strategic plan implementation stage in conjunction with subordinates. Additionally, the leader should help the subordinates in establishing the best path to follow in order to achieve set goals and eliminate possible obstacles that may hinder realization of success. The theory was of relevance to the current study as it contributes to the importance of top management 
support towards implementation of strategies. According to the theory, the management has the responsibility of offering the right leadership geared towards realizing set objectives and goals stipulated in a strategy. When there is right leadership characterized by commitment and employee support within an organization, there is a guarantee of success in the implementation of strategies which then translates into general performance as a result of realizing set goals.

\subsubsection{Policy Theory}

When formulating the theory, Colebatch (2002) aimed at providing an avenue where involved parties in a plan formulates plan's governing policies, designs implementation processes of the formulated policies and evaluates performance of the policies. According to Colebatch (2002), policies that govern formulation and implementation of plans provide stakeholders with a less complex method of monitoring the implementation process. Meier (2009) advanced policy theory and disclosed that emergent discourses identifies stakeholders position, field of action and sets boundaries on the outcomes of the intended policy. The policy theory contributed to the study as it informs on how governments policies can positively or negatively drive successful implementation of strategies in government's institutions. The government formulates policies that govern how public institutions should be run. The nature of policies determines the effectiveness and efficiencies of strategies implementation process which further determines the performance of the institution.

\subsubsection{Conceptual Framework}

The formulation of the conceptual framework is usually made to create a hypothesis abstract at conceptual level in order to enable the results of the research not to be generalized beyond the specific conditions of the particular study. Conceptual schemes designate and or even proscribe, what constitute the characteristics of the research questions and facts (Mugenda and Mugenda, 2008).

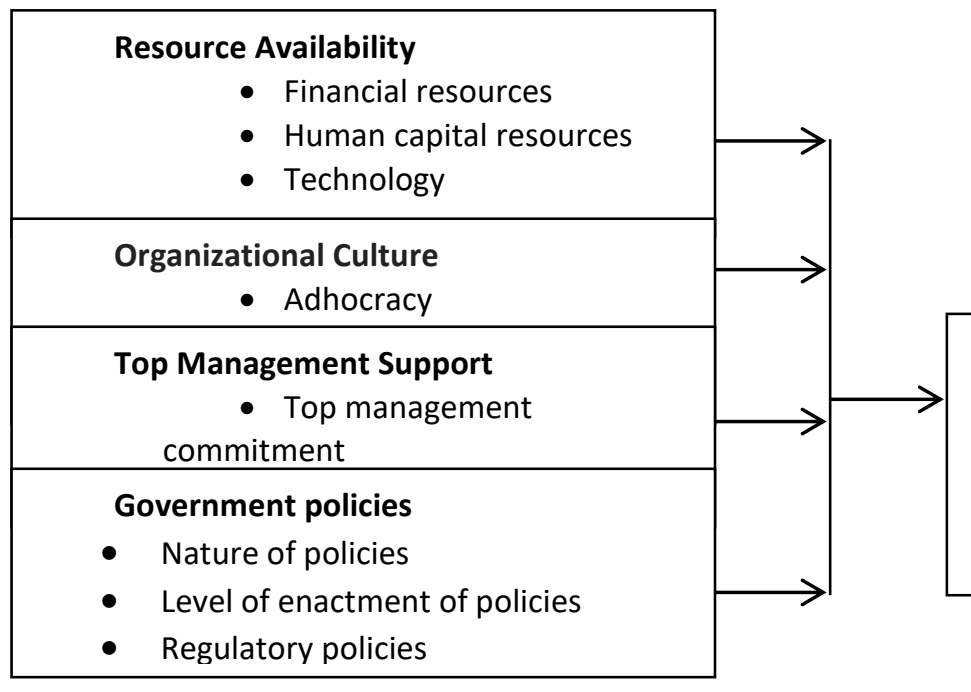

Performance of TARDA

- Number of Completed Development Projects

- Ongoing Projects

- Impact of implementation

Figure 1. Conceptual Framework

\subsection{Empirical review}

The empirical review aims at discussing past studies based on the objectives of the study by reviewing literature on influence of strategic implementation drivers on performance of organizations. Chemwei et al. (2014) sought to evaluate factors that act as impediments to strategic implementation amongst public secondary schools located in Baringo District in Kenya and assess how the impediments hinder performance of schools. The findings of the study revealed that unavailability of resources impede strategic implementation amongst public secondary schools which on the other hand negatively affects the general performance of the schools. The nature of other drivers such as organizational structure and leadership styles were also found to impede the strategic implementation process. 
Another study was conducted by Kevogo and Waiganjo (2015) to assess strategic implementation drivers and performance of private secondary schools with a focus on Thika West Sub County. The study focused on availability and allocation of resources and their subsequent influence on implementation of strategies. The study first revealed the existence of a formulated strategy amongst the schools involved in the study. Secondly, the study revealed a positive correlation between resource availability and allocation and performance of the schools. Abass et al. (2017) sought to establish the existing relationship between implementation of strategic plans and performance of Kenya's County Governments with a case study of Wajir County Government.

The results of the findings revealed that the level of implementation of strategies directly related to the performance of the county government. The study further established that availability of financial resources required in implementation process positively influenced the performance levels of the county government.

Brenes and Schnidt (2008) sought to examine the key success factors for strategy implementation in Latin America. The study sought to evaluate the principles of organization culture and how they drive successful implementation of strategies. The results of the study established that principles of organizational culture determine the success of strategic implementation which translates to performance of manufacturing firms. On the other hand, Awino (2015) conducted an empirical study on selected strategy variables on performance of firms taking a case study of large private manufacturing firms found in Kenya. The findings of the study established that organizational culture, reward system and organizational structure had positive effects on performance of private manufacturing sector. Bett (2016) conducted a study to evaluate the factors that affect strategy implementation in service oriented organizations taking a case study of G4S Kenya Ltd. The study specifically focused on leadership styles, organizational culture and organizational structure and how they influence implementation of strategies. The study findings revealed that organizational culture; organizational structure and leadership styles positively and significantly influenced implementation of strategies in the firm.

Ahnuar (2013) conducted an empirical analysis of policies implications on strategy implementation and performance of construction companies in Malaysia. The analysis of the collected data revealed that strict government policies had negative implications on the implementation of strategies which negatively affected the general performance of the construction companies. Wachira (2016) sought to analyze the level of government involvement in the implementation of strategies in KRA and how the involvement influence revenue collection. The study findings revealed that government involvement in terms of policies and regulations determined the levels of success of strategy implementation.

\section{Methodology of research}

The study adopted a descriptive research design. According to Creswell (2014), a descriptive research is one where data is collected without changing the data collection environment and seeks to answer questions of what, when, where, why and who. Kothari (2013) adds that a descriptive research presents accurate characteristics of people, situations or events and offers a description of how the research strategy connects key objectives of the study and whether the issues under research are policy or theoretical oriented. The study's target population included staffs from TARDA main office occupying top management, middle management and support and technical staff. Stratified random sampling technique was adopted in this study. According to Creswell (2013) stratified sampling technique is probability from where the population under study is divided into strata followed by a random sampling of target units according to defined proportions from the diverse study strata. The study utilized structured questionnaires since according to Mugenda (2008), for the purpose of obtaining either qualitative or quantitative data, the researcher needs to use such questionnaires for generating information on key variables of interest from the targeted respondents in the study.

The questionnaire was divided into two parts covering demographic of respondents and study variables. Kothari (2013) notes that a pilot test refines data collection instruments, by eliminating possible difficulties bound to be faced by respondents. According to Vogt (2010), a pilot test aims at testing reliability and validity of data collection instrument. Cooper and Schindler (2006) argue that a sample of 5- 
$10 \%$ of target population is relevant for pilot study. A pilot study of $10 \%$ (37 questionnaires) of the target population was used for pre-testing. Respondents in the pilot testing were not part of the final study.

After completion of data collection, the collected data was edited for completeness, accuracy, consistency and uniformity and then organized, coded, summarized and tabulated before final analysis. Both inferential statistics and descriptive statistics was applied in analyzing the data using Percentages, standard deviation and mean. It was then analyzed quantitatively using SPSS Multivariate correlation and regression coefficient was used to analyze the relationship between the dependent variable and the independent variables. The following multivariate model was used in the study:

$$
Y=\beta_{0}+\beta_{1} X_{1}+\beta_{2} X_{2}+\beta_{3} X_{3}+\beta_{4} X_{4}+\varepsilon
$$

Where:

$Y=$ Performance of TARDA; $X_{1}=$ Resource Availability; $X_{2}=$ Organizational Culture; $X_{3}=$ Top Management Support; $X_{4}=$ Government Policies;

$\beta_{0}=$ Regression Constant or Intercept; $\beta_{1}, \beta_{2}, \beta_{3}$ and $\beta_{4}=$ are the unknown coefficients of independent variables. $\mathcal{E}=$ error term assumed to be normally distributed with a zero variance.

The study also conducted diagnostic tests to ensure that the assumptions of ordinary least square were satisfied before conducting a multiple linear regression analysis. The tests carried out were the normality, linearity and multicollinearity test. The study used a correlation matrix to determine the presence of Multicollinearity among the independent variables before running the regression model.

\section{Research findings and discussions}

A total of 189 questionnaires were administered to the target respondents comprising of employees in the top, middle and lower management levels. A total of 149 questionnaires were fully filled and returned. This represented response rate of $78.8 \%$. The pilot test was conducted on $10 \%$ of the target population which comprised of 37 respondents. The respondents were randomly selected from the three managerial positions. Creswell (2003) highly advocates for pilot study by researchers since the test evaluates the level of reliability and validity of questionnaires.

The study adopted Cronbach Alpha value to test for reliability while content validity was adopted in testing for validity. The final study excluded the respondents who were involved in the piloting. According to Creswell (20003), reliability measures the extent to which data collection instrument yields consistent result when applied severally on similar tests. The results of the reliability tests shows that all the constructs of the study variables included in the current study had an alpha value of above 0.7 . This implies presence of consistency amongst the questionnaires. Cronbach (1951) asserts that an alpha value of 0.7 is taken as a threshold where a value equals to or is greater than 0.7 is considered reliable.

Table 1. Reliability Test Results

\begin{tabular}{lccc}
\hline Scale & Cronbach's Alpha & Number of Items & Comment \\
\hline Resource Availability & 0.854 & 7 & Reliable \\
Organizational Culture & 0.794 & 8 & Reliable \\
Top Management Support & 0.893 & 7 & Reliable \\
Government Policies & 0.865 & 7 & Reliable \\
Performance of TARDA & 0.839 & 9 & Reliable \\
\hline
\end{tabular}

\subsection{Descriptive results}

In this section the study analyzed resource availability, Organizational Culture, Top Management Support and government policies using descriptive statistics. The study used percentages, mean and standard deviation to analyze the response based on the statements used to measure the study variables including the dependent variable. The study rated the responses from a scale of 1-5 where $5=$ Strongly Agree (SA); 4 = Agree (A); 3= Neutral (N); 2= Disagree (D) and 1= Strongly Disagree (SD) and presented the mean response per statement for all the study variables. In this study, a value of less than 2.5 was interpreted as disagree while a value above 3.5 was interpreted as agree. A value between 2.5 and 3.4 was interpreted as neutral. 


\section{Resource Availability}

The researcher requested the respondents to indicate their levels of agreement with statements on resource availability. The results are presented in table 2 which shows that on average, respondents were neutral with statements pertaining to resource availability as shown by average response mean of 3.29 and average standard deviation of 1.31. This is consistent with Thompson et al., (2010) who posits that in strategic management, elements of human resource play a crucial role in the design, implementation and administration of strategies.

Table 2. Descriptive Statistics on Resource Availability

\begin{tabular}{|c|c|c|c|}
\hline Statement & Response rate & Mean & Std.Dev \\
\hline $\begin{array}{l}\text { The Authority receives adequate funding from the Exchequer for } \\
\text { implementation of strategies }\end{array}$ & 149 & 2.41 & 1.79 \\
\hline $\begin{array}{l}\text { The Authority allocates sufficient financial resources for implementation of } \\
\text { strategies }\end{array}$ & 149 & 1.99 & 1.98 \\
\hline The Authority relies mainly on financial resources in implementing strategies & 149 & 3.87 & 1.02 \\
\hline There is adequate human capacity to implement the organization's strategies & 149 & 3.46 & 1.21 \\
\hline Employees have adequate skills relevant for the implementation process & 149 & 3.44 & 1.23 \\
\hline $\begin{array}{l}\text { There are training sessions on employees before the start of the } \\
\text { implementation process }\end{array}$ & 149 & 3.97 & 0.95 \\
\hline $\begin{array}{l}\text { The Authority has adopted relevant technology for the implementation } \\
\text { process }\end{array}$ & 149 & 3.89 & 0.96 \\
\hline Average & 149 & 3.29 & 1.31 \\
\hline
\end{tabular}

\section{Organizational Culture}

The researcher was to establish how organization culture influences the performance of TARDA from the respondents. On average, respondents agreed with the statements on organizational culture as shown by average response mean of 4.025 and average std. dev of 0.915 . The results concur with Saunders (2008) who noted that successful implementation of strategies depends largely on the culture of the organization as it is through culture that determines how an organization develops its business, relationship with business partners, customers and clients.

Table 3. Descriptive Statistics on Organization Culture

\begin{tabular}{|c|c|c|c|}
\hline Statement & Response rate & Mean & Std.Dev \\
\hline $\begin{array}{l}\text { The organization emphasizes on self-organization on employees in } \\
\text { accomplishing task }\end{array}$ & 149 & 4.13 & 0.83 \\
\hline The organization emphasizes on individual initiatives when accomplishing task & 149 & 3.98 & 0.97 \\
\hline Execution of activities in our organization is based on creativity & 149 & 3.97 & 0.98 \\
\hline $\begin{array}{l}\text { Managers in our organization offer mentorship programs to junior employees } \\
\text { on the ways and means to carry out set activities }\end{array}$ & 149 & 4.11 & 0.84 \\
\hline $\begin{array}{l}\text { There is emphasis on collaboration in the execution of set activities with the } \\
\text { aim of achieving common goals }\end{array}$ & 149 & 4.04 & 0.87 \\
\hline Our organization has established structures that guides execution of activities & 149 & 4.02 & 0.88 \\
\hline Our culture encourages employees loyalty and sense of belonging & 149 & 3.98 & 0.97 \\
\hline $\begin{array}{l}\text { The organization has supportive culture that overcome internal resistance to } \\
\text { change }\end{array}$ & 149 & 3.97 & 0.98 \\
\hline Average & 149 & 4.025 & 0.915 \\
\hline
\end{tabular}

\section{Top Management Support}

The researcher also requested the respondents to indicate their agreement levels with statements pertaining to top management asses the influence of top management support on performance of TARDA On average, respondents agreed with the statements on top management support as shown by average response mean of 3.87 and average std. dev of 0.97 . 
Table 4. Descriptive Statistics on Top Management Support

\begin{tabular}{lccc}
\hline \multicolumn{1}{c}{ Statement } & Response Rate & Mean & Std.Dev \\
\hline The management is committed to the implementation of strategies & 149 & 4.12 & 0.8 \\
The management prioritizes on implementing the strategies & 149 & 4.01 & 0.87 \\
$\begin{array}{l}\text { Management help employees with means to discharge their duties } \\
\text { successfully }\end{array}$ & 149 & 4.01 & 0.87 \\
$\begin{array}{l}\text { Managers practice participatory leadership in the process of implementing } \\
\text { strategies }\end{array}$ & 149 & 3.96 & 0.94 \\
Management fairly rewards good performers in our organization & 149 & 3.78 & 1.04 \\
Poor performers are fairly reprimanded by management in our organization & 149 & 3.36 & 1.29 \\
Incentives positively influence performance of employees in our organization & 149 & 3.86 & 0.98 \\
$\quad$ Average & $\mathbf{1 4 9}$ & $\mathbf{3 . 8 7}$ & $\mathbf{0 . 9 7}$ \\
\hline
\end{tabular}

\section{Government Policies}

The other objective of the researcher was to determine how the government policies influence performance of TARDA. On average, respondents were in agreement with statements on government policies as shown by average response mean of 3.93 and average std. dev of 0.97 . The results concurs with Bordoloi (2014) who noted that policies allow managers and subordinate staff to know what is expected from them and guides them towards achieving those expectations.

Table 5. Descriptive Statistics on Government Policies

\begin{tabular}{|c|c|c|c|}
\hline Statement & Response Rate & Mean & Std.Dev \\
\hline $\begin{array}{l}\text { There are favorable government policies that guide the strategic plan } \\
\text { implementation process }\end{array}$ & 149 & 3.98 & 0.94 \\
\hline $\begin{array}{l}\text { Various government policies results in conflicts with the operations in the } \\
\text { organization }\end{array}$ & 149 & 3.85 & 1.01 \\
\hline $\begin{array}{l}\text { The requirement of various policies affects the organization's ability of } \\
\text { implementing strategies }\end{array}$ & 149 & 3.87 & 1 \\
\hline $\begin{array}{l}\text { The organization ensures full enactment of policies formulated by the } \\
\text { government }\end{array}$ & 149 & 3.94 & 0.96 \\
\hline $\begin{array}{l}\text { There is a contradiction between organizational policies and government } \\
\text { stipulated policies }\end{array}$ & 149 & 3.84 & 1.01 \\
\hline $\begin{array}{l}\text { The organization follows strict regulatory policies when implementing its } \\
\text { strategies }\end{array}$ & 149 & 3.97 & 0.95 \\
\hline \multirow{2}{*}{$\begin{array}{l}\text { Government policies influence implementation of strategies in } \\
\text { organization }\end{array}$} & 149 & 4.06 & 0.9 \\
\hline & 149 & 3.93 & 0.97 \\
\hline
\end{tabular}

\section{Performance of TARDA}

The researcher requested respondents to indicate their agreement levels with statements pertaining to performance of the Authority as presented in table 7. On average, respondents were neutral on the statements pertaining to performance of TARDA as shown by average response mean of 3.41 and average std. dev of 1.25 .

Table 7. Descriptive Statistics on Performance of TARDA

\begin{tabular}{|c|c|c|c|}
\hline Statements & Response Rate & Mean & Std.Dev \\
\hline $\begin{array}{l}\text { The organization has managed to successfully complete a considerable number } \\
\text { of projects }\end{array}$ & 149 & 3.85 & 1.01 \\
\hline $\begin{array}{l}\text { The organization has managed to commission the projects and they are } \\
\text { functional }\end{array}$ & 149 & 3.1 & 1.46 \\
\hline The organization has ongoing projects which are in good progress & 149 & 3.45 & 1.23 \\
\hline The projects have benefited the targeted number of beneficiaries. & 149 & 3.32 & 1.29 \\
\hline The projects have covered the intended area of coverage & 149 & 3.43 & 1.24 \\
\hline The Projects have managed to produce the targeted output & 149 & 3.33 & 1.28 \\
\hline Average & 149 & 3.41 & 1.25 \\
\hline
\end{tabular}




\section{Inferential Statistics}

This section presents the inferential statistics, comprising of both correlation and regression analysis. Inferential statistics according to Mugenda and Mugenda (2013) aims at establishing existence of further relationships between the variables of the study.

\subsection{Correlation results}

The study sought to establish how independent variables (resource availability, organizational culture, top management support and government policies) influence dependent variable (performance of TARDA). The results of the analysis are as presented in table 8.

Table 8. Correlation Analysis

\begin{tabular}{|c|c|c|c|c|c|c|}
\hline & & $\begin{array}{c}\text { Resource } \\
\text { Availability }\end{array}$ & $\begin{array}{l}\text { Organizational } \\
\text { Culture }\end{array}$ & $\begin{array}{l}\text { Top Management } \\
\text { Support }\end{array}$ & $\begin{array}{l}\text { Government } \\
\text { Policies }\end{array}$ & $\begin{array}{l}\text { Performance of } \\
\text { TARDA }\end{array}$ \\
\hline $\begin{array}{c}\text { Resource } \\
\text { Availability }\end{array}$ & $\begin{array}{c}\text { Pearson } \\
\text { Correlation } \\
\text { Sig. (2-tailed) }\end{array}$ & 1 & & & & \\
\hline $\begin{array}{l}\text { Organizational } \\
\text { Culture }\end{array}$ & $\begin{array}{l}\text { Pearson } \\
\text { Correlation } \\
\text { Sig. (2-tailed) }\end{array}$ & -0.181 & 1 & & & \\
\hline $\begin{array}{l}\text { Top Management } \\
\text { Support }\end{array}$ & $\begin{array}{l}\text { Pearson } \\
\text { Correlation }\end{array}$ & -0.139 & -0.273 & 1 & & \\
\hline & Sig. (2-tailed) & 0.421 & 0.096 & & & \\
\hline $\begin{array}{l}\text { Government } \\
\text { Policies }\end{array}$ & $\begin{array}{l}\text { Pearson } \\
\text { Correlation }\end{array}$ & -0.107 & 0.128 & $.021^{* *}$ & 1 & \\
\hline $\begin{array}{l}\text { Performance of } \\
\text { TARDA }\end{array}$ & $\begin{array}{l}\text { Sig. (2-tailed) } \\
\text { Pearson } \\
\text { Correlation }\end{array}$ & $.546 * *$ & $.254^{* *}$ & $.389 * *$ & $-.101 * *$ & 1 \\
\hline & Sig. (2-tailed) & 0 & 0.009 & 0.002 & 0.172 & \\
\hline & $\mathrm{N}$ & 149 & 149 & 149 & 149 & 149 \\
\hline
\end{tabular}

The correlation results show that resource availability and performance of TARDA correlates as shown by a correlation value of 0.546 and a $p$-value of 0.000 . The results means that the correlation is positive and significant implying that increase in resource availability increases performance of TARDA. The findings are consistent with Thompson et al. (2010) who posits that in strategic management, elements of human resource play a crucial role in the design, implementation and administration of strategies.

The results of correlation further indicate that the correlation between organizational culture and performance of TARDA is 0.254 and a p-value of 0.009 . The results mean that the correlation is positive and significant implying that increase in the practices of organizational culture increases performance of TARDA. The findings are consistent with Saunders (2013) who noted that successful implementation of strategies depends largely on organizational culture characterized by forms such as adhocracy, clan and hierarchy culture. The correlation results also indicate that the correlation between top management support and performance of TARDA is 0.389 and a $p$-value of 0.002 . The results mean that the correlation is positive and significant implying that increase in top management support increases performance of TARDA. The findings are consistent with Kauffman and Rapa (2015) who asserts that the level of commitment of top level management staff to the direction of the strategic plan is one of the most significant and instrumental factor in the implementation of the strategies.

The results of correlation analysis finally revealed that the correlation between government policies and performance of TARDA is -0.101 and a $p$-value of 0.172 . This means that government policies and performance of TARDA negatively correlates. The findings concur with Malik and Kotabe (2009) who pointed out that government policies set limits, constraints and boundaries on the nature of administrative action that ought to be taken in the course of executing an activity and clarifies the do's and don'ts in the pursuit of implementing the strategies. 
A multiple linear regression analysis was adopted in the current study to assess the statistical relationships between independent variables (resource availability, organizational culture, top management support and government policies) and dependent variable (performance of TARDA). The study used a confidence level of $95 \%(\alpha=0.05)$. Table 9 presents the regressions analysis results. The results shows existence of a strong relationship between independent variables and dependent variable as shown by $R=.774$. $R$-square, the coefficient of determination, was .599 implying that $59.9 \%$ of variation in performance of TARDA can be explained by resource availability, organizational culture, top management support and government policies.

Table 9. Model Summary

\begin{tabular}{cccc}
\hline $\mathbf{R}$ & R Square & Adjusted R Square & Std. Error of the Estimate \\
\hline $.774^{\text {a }}$ & 0.599 & 0.561 & 0.121 \\
\hline
\end{tabular}

The ANOVA test results are presented in table 10. According to the results, the overall model linking resource availability, organizational culture, top management support and government policies with performance of TARDA was statistically significant. The statistical significance is confirmed by comparing the value of $F$ calculated and the value of $F$ critical. The $F$ calculated value (29.224) exceeds $F$ critical value (2.3719) implying that the overall model is statistically significant at $5 \%$ significant level. The significance level is supported by Dye (2009) who postulated that a model becomes statistically significant if the value of $F$ calculated exceeds the value of $F$ critical from $f$-statistical tables.

Table 10. ANOVA (Model Significance)

\begin{tabular}{cccccc}
\hline & Sum of Squares & df & Mean Square & F & Sig. \\
\hline Regression & 7.411 & 4 & 1.8528 & 29.224 & 0.000 \\
Residual & 9.124 & 144 & 0.0634 & & \\
Total & $\mathbf{1 6 . 5 3 5}$ & $\mathbf{1 4 8}$ & & & \\
\hline
\end{tabular}

Table 11 presents the coefficients of the model. The results shows that resource availability has a positive and significant influence on performance of TARDA as shown by $\beta=0.593$ and Sig $=0.000<0.05$. This implies that a unit change in resource availability results to an increase of 0.593 units in the performance of TARDA. The coefficient results also shows that organizational culture has a positive and significant influence on performance of TARDA as shown by $\beta=0.202$ and Sig $=0.004<0.05$. This implies that a unit change in the organizational culture practices results to an increase of 0.202 units in the performance of TARDA. The findings concur with Brenes and Schnidt (2014) on examining the key success factors for strategy implementation in manufacturing firms found in Latin America and concluded that organizational culture with supportive values and clan culture in line with the formulated strategy culminated to improved performance of the manufacturing firms.

The coefficient results further shows that top management support bears a positive and significant influence on performance of TARDA as shown by $\beta=0.391$ and Sig $=0.000<0.05$. This implies that a change in one unit on the practices of top management support results to an increase of 0.391 units in the performance of TARDA. The findings are consistent with Aosa (2013) on his study to assess how strategy implementation affect the performance of the manufacturing sector in Kenya which revealed that top management plays a significant role in the formulation and implementation of strategies which bears a positive effect on the performance of the firms.

The coefficient results finally revealed that government policies is significant but negatively influences performance of TARDA as shown by $\beta=-0.146$ and Sig $=0.004<0.05$. This implies that a unit change in government policies results to a decrease of 0.146 units in the performance of TARDA. The government policies are significant, but due to the nature of stiff regulatory policies in place and others which conflict with the mandate of the organization, this has led to the negative performance of TARDA. The findings concur with Ahnuar (2013) on his empirical analysis of policies implications on strategy implementation and performance of construction companies in Malaysia and revealed that government policies had negative implications on the implementation of strategies which negatively affected the general performance of the construction companies. 
Table 11. Model Coefficients

\begin{tabular}{lccccc}
\hline & \multicolumn{3}{c}{ Unstandardized Coefficients } & \multicolumn{3}{c}{ Standardized Coefficients } \\
\hline \multicolumn{1}{c}{ Predictors } & B & Std. Error & Beta & t & Sig. \\
\hline (Constant) & 0.263 & 0.131 & & 2.015 & 0.001 \\
Resource Availability & 0.593 & 0.186 & 0.448 & 3.188 & 0.000 \\
Organizational Culture & 0.202 & 0.102 & 0.191 & 1.980 & 0.004 \\
Top Management Support & 0.391 & 0.156 & 0.246 & 2.506 & 0.000 \\
Government Policies & -0.146 & 0.102 & -0.161 & 1.431 & 0.004 \\
\hline
\end{tabular}

\section{Conclusions}

The study findings led to conclusions that resource availability positively and significantly influence performance of TARDA. The study further established that practices such as availing adequate financial resources when implementing strategies, having training sessions on employees before the start of the implementation process and adopting relevant technology for the implementation process by the Authority positively and significantly influences performance of TARDA. The study findings also led to conclusions that organizational culture positively and significantly influence performance of TARDA. The study further established that practices emphasizing on self-organization on employees in accomplishing task, emphasizes on individual initiatives when accomplishing task, executing activities basing on creativity, offering mentorship programs to junior employees on the ways and means to carry out set activities, emphasizing on collaboration in the execution of set activities with the aim of achieving common goals, establishing structures that guides execution of activities, having a culture that encourages employees loyalty and sense of belonging and having a supportive culture that overcome internal resistance to change positively and significantly influences performance of TARDA.

The study findings further led to conclusions that top management support positively and significantly influence performance of TARDA. The study further established that practices such as commitment to the implementation of strategies by the management, prioritizing on implementing the strategies, helping employees with means to discharge their duties successfully, practicing participatory leadership in the process of implementing strategies, rewarding fairly good performers and having incentives that positively influence performance of employees in the Authority positively and significantly influences performance of TARDA. The study findings finally led to conclusions that government policies negatively influence performance of TARDA. The study further established that there are favourable government policies that guide the strategic plan implementation process. However, various government policies have resulted in conflict with the operations in the organization and therefore affecting the organization's ability to implement the laid down strategies.

\section{Recommendations}

This section presents study's recommendations based on the conclusions and research findings. The recommendations are presented in respect to each research objective. The recommendations are directed to the management of TARDA and other authorities. The study recommends that the management of TARDA should focus on availing resources since the practice has a positive and significance influence on performance of the Authority. The Authority can achieve this by diversifying its financial resource base when implementing strategies rather than mainly relying on the government, having training sessions on employees before the start of the implementation process and adopting relevant technology for the implementation process by the Authority.

The study also recommends that the management of TARDA should focus on enhancing its organizational culture since the practice has a positive and significance influence on performance of the Authority. The Authority can achieve this by emphasizing on self-organization on employees in accomplishing task, emphasizes on individual initiatives when accomplishing task and offering mentorship programs to junior employees on the ways and means to carry out set activities. 
The management should also emphasize on collaboration in the execution of set activities with the aim of achieving common goals, establishing structures that guides execution of activities, having a culture that encourages employees' loyalty and sense of belonging and having a supportive culture that overcome internal resistance to change. The study further recommends that the management of TARDA should focus on enhancing its top management support in the implementation of strategies since the practice has a positive and significance influence on performance of the Authority. The Authority can achieve this by being committed to the implementation of strategies by the management, prioritizing on implementing the strategies, helping employees with means to discharge their duties successfully, practicing participatory leadership in the process of implementing strategies, rewarding fairly good performers and having incentives that positively influence performance of employees in the Authority.

\section{References}

1. Abass, M. K., Munga, J. \& Were, E. (2017). The relationship between strategy implementation and performance in county governments of Kenya: A case study of Wajir County government. International Academic Journal of Human Resource and Business Administration, 2(3), 381-401

2. Acar, T. O. E. (2013). Organizational culture: the case of Netherlands Construction Industry. Engineering, Construction and Architectural Management, 14(6),519-531

3. Ahnuar, E.M. (2013). An empirical analysis of implications of government policies on implementation of strategies and the effects on performance of construction Companies in Malaysia. International Journal of Earth and Environmental science. 34(117), 889-905

4. Alexander, L. D. (2011), Successfully implementing strategic decisions, Long Range Planning. Journal of Business Management, 18(3), 91-97

5. Aosa, E. (2013). An empirical investigation on how strategy implementation drivers affect the performance of the manufacturing sector in Kenya. Strathclyde University: Unpublished PhD thesis

6. Awino, Z. B. (2015). An empirical investigation of selected strategy variables on firms performance: A study of supply chain management in large private manufacturing firms in Kenya. Journal of Public Administration and Policy Research 3 (8), 228-236

7. Barney, J. (1991). Firm Resources and Sustained Competitive Advantage. Journal of Management. 17, 99-120.

8. Barney, J. (2000). Is the resource-based view a useful perspective for strategic management research? Yes. Academy of Management Review. 26, 41-56.

9. Beer, M., Eisenstat, R. (2010), The silent killers of strategy implementation and learning, Sloan Management Review, 41, 29-40.

10.Bett, E. K. (2016). Factors Affecting Strategy Implementation In Service Oriented Organizations: A Case Study Of G4s Kenya Limited. Unpublished Master's Thesis: United States International University Africa

11.Bordoloi, R. (2014). Formulation and Implementation of Government Strategic Policies and Programmes with Reference to Assam. Arthshastra: Indian Journal of Economics \& Research, 3(1), 40.

12.Brenes, M., \& Schnidt, S. L. (2008). Key Success Factors for Strategy Implementation in Latin America. Journal of Business Research, 61(6), 590 - 598, 8.

13.Chemwei, B., Leboo,C., \& Koech, S.J. (2014). Factors that impede the implementation of strategic plans in secondary schools in Baringo Distict, Kenya. International Journal of Humanities and Social Science. $4(5), 144-120$

14.Colebatch, H. K. (2002). Policy, Open University Press, Buckingham, U.K.

15.Cooper, D. R., \& Schindler, P. S. (2006). Business Research Methods ( $9^{\text {th }}$ edition). USA: McGrawHill.

16.Creswell, J. W., Plano Clark, V. L., Guttmann, M. L., \& Hanson, W. E. (2003). Advanced mixed methods research designs. Handbook of mixed methods in social and behavioral research, 209, 240.

17.Heide, M., Grønhaug, K. \& Johannessen, S. (2012). Exploring barriers to the successful implementation of a formulated strategy. Scandinavian Journal of Management, 18, 217-231. 
18.James, R., \& Jones, G. (2005). The Character of a Corporation: How Your Company's Culture Can Make or Break Your Business, London: Harper Business.

19.Kevogo, A. A., \& Waiganjo, E. (2015). Strategic implementation drivers and performance of private secondary schools in Kenya: A survey of Private secondary schools in Thika west sub-county. Strategic journal of business management, 2(2), $1899-1914$

20.Kothari, C. R. (2013). Research design: Qualitative, quantitative, and mixed methods approach. New Age International. New Delhi, 12-15.

21.Malik, O., \& Kotabe, M. (2009). Dynamic Capabilities, Government Policies, and Performance in Firms from Emerging Economies: Evidence from India and Pakistan. Journal of Management Studies, 46(3), 421-450.

22.Meier, K. (2009). Policy Theory, Policy Theory Everywhere: Ravings of a Deranged Policy Scholar. Policy Studies Journal, 37(1), 5-11.

23.Mueni, J. (2016). Factors Influencing the Strategic Implementation of Change Management in the Devolved Public Health Services in Kenya: A Case of Nakuru Provincial General Hospital. International Journal of Science and Research (IJSR), 5(4), 1707-1713.

24.Mugenda, A. G. (2008). Social science research: Theory and principles. Nairobi: Applied.

25.Mugenda, O., \& Mugenda, A. (2013). Research methods. Nairobi, Kenya: African Centre for Technology Studies.

26.Ogonge, J. (2013). Relationship between Strategic Planning and Organization's Performance in Non-Governmental Organization (NGOs). A Case of Action Aid, Kenya.

27.Penrose E.T. (1959). The Theory on the performance of the firm. Oxford University Press: New York

28.Saunders, M., R., M., \& R., S. (2008). Implementing Strategic Initiatives: A Framework of Leading Practices. International Journal of Operations and Production Management 28(11), 1095 - 1123

29.Tana and Athi River Development Authority Report (2009)

30.Tana and Athi River Development Authority Report (2014)

31.Tana and Athi River Development Authority Report (2018)

32.Thompson, A. A., Jr., Strickland III, A. J. \& Gamble, J E. (2012). Crafting and executing strategy: The Quest for Competitive Advantage. Concepts and Cases (15th ed.). New York: McGraw-Hill Irwin

33. Thompson, A. A., Strickland, A.J., \& Gamble, J. E. (2013). Crafting and Executing Strategy - Texts and Readings. (15th Ed.). New York: McGraw-Hill Irwin.

34. Vogt, W. (2010). Data collection. Los Angeles: SAGE.

35. Wachira, C. (2016) An analysis of the level of government involvement in the implementation of strategies in Kenya Revenue Authority and how the involvement influence revenue collection. Unpublished Master's Thesis: University Of Nairobi. 